molecular mechanisms underlying CS insensitivity are not fully known. Here, we hypothesise that reduction in the expression of the Glucocorticoid receptor (GR) and Importin 7 are related to CS insensitivity. This aims project were to compare the gene expression of GR and Importin 7 between severe asthmatics and mild/moderate asthmatics or healthy controls of the U-BIOPRED cohort. We then investigated whether changes in their expression, correlated with changes in clinical features and expression of other genes.

Methods The U-BIOPRED database contains data on mRNA expression, lung function, medication usage, blood, urine and sputum samples for their subjects $(n=611)$. Using an unbiased approach to analyse the data we will initially used Gene Set Variation Analysis (GSVA) to look for differences in expression of GR and Importin 7 between the severe asthma, mild/moderate asthma and healthy volunteer cohorts. We then characterised the asthmatics into subjects with high (top 25\%, compared to healthy controls) or low (bottom 25\%) expression of GR or Importin 7 and then compared clinical characteristics and gene expression profiles between the high and low expressing GR or Importin-7 groups.

Results Severe and non-severe asthmatics had reduced GR expression in endobronchial biopsy and brushings samples compared to healthy controls. There were no significant differences in lung function, blood analytes or exacerbation rates between high or low GR expression groups. Severe non-smoking asthmatics had reduced Importin 7 expression in sputum compared to mild/moderate asthmatics and healthy controls. Low Importin 7 group had lower means in FEV1\%, FEV1/ FVC, higher means in blood and sputum neutrophils\%, IL-6 and hCRP.

Conclusions Reduced Importin-7 expression in sputum samples of asthmatics correlated with reduced lung function scores, increased neutrophilic inflammation and more oral CS use.

\section{S65 QUANTIFICATION OF 'WHOLE LUNG' PULMONARY EOSINOPHILIC INFLAMMATION USING RADIOLABELLED AUTOLOGOUS HUMAN EOSINOPHILS}

${ }^{1} \mathrm{~N}$ Farahi, ${ }^{1} \mathrm{~S}$ Loutsios, ${ }^{1} \mathrm{~N}$ Tregay, ${ }^{2}$ AKA Wright, ${ }^{1} \mathrm{LSC}$ Lok, ${ }^{3} \mathrm{D}$ Gillett, ${ }^{3} \mathrm{I}$ Cullum, ${ }^{1} \mathrm{RP}$ Simmonds, ${ }^{1} \mathrm{C}$ Summers, ${ }^{3} \mathrm{~A}$ Wong, ${ }^{3} \mathrm{CK}$ Solanki, ${ }^{3} \mathrm{~J}$ Buscombe, ${ }^{2} \mathrm{PH}$ Pang, ${ }^{1} \mathrm{~A}$ Thavakumar, ${ }^{4} \mathrm{AM}$ Peters, ${ }^{2} \mathrm{CE}$ Brightling, ${ }^{1} \mathrm{AM}$ Condliffe, ${ }^{1} \mathrm{ER}$ Chilvers. ${ }^{1}$ University of Cambridge, Cambridge, UK; ${ }^{2}$ University of Leicester, Leicester, UK; ${ }^{3}$ Addenbrooke's Hospital, Cambridge, UK; ${ }^{4}$ Brighton and Sussex Medical School, Brighton, UK

10.1136/thoraxjnl-2017-210983.71

Background Eosinophils are key mediators of allergic inflammation. The ability to localise and quantify eosinophilic inflammation in vivo would facilitate patient endotyping and evaluation of eosinophil-targeted therapeutics. We aimed to quantify eosinophil distribution and organ-specific uptake in healthy subjects, asthmatics, and patients with focal pulmonary eosinophilic inflammation.

Methods We injected autologous radiolabelled eosinophils into 8 healthy volunteers, 15 asthmatics (7 obese and 7 non-obese), and 3 patients with focal eosinophilic inflammation and monitored eosinophil distribution (planar imaging, single photon emission computed tomography - SPECT)/CT). Lung accumulation of technetium-99 m-labelled eosinophils was quantified (Patlak-Rutland analysis). Whole body indium-111-labelled eosinophil distribution and loss were further assessed in 5 healthy volunteers and 7 asthmatics using a whole body counter.
Findings Pulmonary eosinophil clearance was increased in patients with focal eosinophilia $(0.0033 \mathrm{ml} / \mathrm{min} / \mathrm{ml} ; 95 \% \mathrm{CI}$ $-0.005-0.011 ; \mathrm{p}=0.02)$ compared to asthmatics $(0.0007 \mathrm{ml} /$ $\mathrm{min} / \mathrm{ml} ; \quad 95 \% \mathrm{CI} \quad 0.0003-0.0010 ; \quad \mathrm{p}=0.14)$ and controls $\left(0.0003 \mathrm{ml} / \mathrm{min} / \mathrm{ml} ; 95 \%\right.$ CI $\left.-7.5 \times 10^{-5}-0 \cdot 0008\right)$. Absolute lung eosinophil migration was elevated in patients with focal inflammation $(5932$ eosinophils $/ \mathrm{min} / \mathrm{ml} ; \quad 95 \%$ CI $-14351-$ 26215, $\mathrm{p}=0.01$ ) and asthma (364 eosinophils $/ \mathrm{min} / \mathrm{ml} ; 95 \% \mathrm{CI}$ $38-689 ; \mathrm{p}=0.03)$ versus healthy volunteers (38 eosinophils/ $\mathrm{min} / \mathrm{ml}$; 95\% CI -11-87). Stratification of asthmatics based on BMI revealed increased pulmonary eosinophil clearance in obese $(0.001 \mathrm{ml} / \mathrm{min} / \mathrm{ml} ; 95 \%$ CI $0 \cdot 0007-0 \cdot 001 ; \mathrm{p}=0.02)$ versus non-obese asthmatics $(0.0003 \mathrm{ml} / \mathrm{min} / \mathrm{ml} ; \quad 95 \% \mathrm{CI}$ $-0 \cdot 0002-0 \cdot 0009)$.

Interpretation Eosinophil radiolabelling can quantify pulmonary eosinophilic inflammation, with the potential for patient endotyping and testing eosinophil-targeted treatments.

Funding Medical Research Council, Wellcome Trust, Asthma UK, Cambridge NIHR Biomedical Research Centre.

\section{S66 LONG-TERM AZITHROMYCIN THERAPY IMPROVES CLINICAL OUTCOMES IN AN INFECTIVE PHENOTYPE OF SEVERE ASTHMA}

K Ibrahim, AH Mansur. Birmingham Heartlands Hospital, Birmingham, UK

\subsection{6/thoraxjnl-2017-210983.72}

Introduction Azithromycin is a macrolide with antibiotic and anti-inflammatory properties, which may reduce exacerbations and improves clinical outcomes in severe asthma. However, the target population and clinical utility of azithromycin in real life setting remain uncertain.

Aim To determine the efficacy and safety of long-term azithromycin treatment in severe asthma in real life setting.

Methods Patients attended a tertiary severe asthma between 2013 to 2016 were clinically characterised using pre-designed protocol and data were recorded on the dendrite system. The clinical outcomes of patients treated by long-term azithromycin ( $\geq 4$ months) were compared for the 12 months before and 12 months on treatment using parametric and non-parametric analysis.

Results Out of a total number of 259 patients entered on the registry, $46(17.7 \%)$ patients had long- term azithromycin treatment. The mean age of this group was 50 years. (range 25-72), 33 (66\%) females, mean BMI $32 \pm 8.4 \mathrm{~kg} / \mathrm{M}^{2}, 41$ $(80 \%)$ had infective phenotype $(\geq 4$ LRTI per annum and/or chronic productive cough), 13 (23\%) had CT-scan confirmed bronchiectasis, mean ICS $1620 \mathrm{mcg} / \mathrm{day}$ and 13 (26\%) were on maintenance OCS. The mean FEV1=1.96 L $\pm 0.73, \%$ predicted $\mathrm{FEV} 1=69.4 \pm 24.3$, mean $\mathrm{FEV} 1 / \mathrm{FVC}$ ratio $64.6 \pm 16.5$, mean FeNO $26 \pm 27.2 \mathrm{ppb}$, mean blood eosinophil $0.3 * 10^{9} / 1$, and mean blood neutrophil was $6.2 \pm 2.2 * 10^{9} / 1$. We observed significant reduction in the mean number of OCS requiring exacerbation in the 12 months on treatment compared to the 12 months pre-treatment (figure 1). There was also significant reduction in LRTI frequency from median $=4.5$ per annum to $1.0(\mathrm{p}<0.00001)$ and hospital admissions from mean of 1.17 \pm 2.4 to $0.24 \pm 0.7 \quad(p=0.01)$. Also statistically non-significant improvement in ACQ-7 mean $3.5 \pm 1.26$ to $3.18 \pm 1.3 \quad(p=0.09)$ and FEV1 1.72 to $1.91(\mathrm{p}=0.36)$. The treatment was generally well tolerated with $35(76 \%)$ of patients had positive 